\title{
The relationship between function and sexual satisfaction with sexual violence among women in Ahvaz, Iran
}

\author{
Mitra Tadayon ${ }^{1}$, Zahra Hatami-Manesh ${ }^{2}$, Nasibeh Sharifi ${ }^{3}$, Shahnaz Najar ${ }^{1}$, Azadeh Saki $^{4}$, Zahra Pajohideh $^{5}$
}

${ }^{1}$ M.Sc. of Midwifery, Menopause Andropause Research Center, Ahvaz Jundishapur University of Medical Sciences, Ahvaz, Iran

${ }^{2}$ M.Sc. of Midwifery, Department of Midwifery, Menopause Andropause Research Center, Ahvaz Jundishapur University of Medical Sciences, Ahvaz, Iran

${ }^{3} \mathrm{Ph} . \mathrm{D}$. of Reproductive Health, Assistant Professor, Department of Midwifery, School of Nursing \& Midwifery, Ilam University of Medical Sciences, Ilam, Iran

${ }^{4}$ Ph.D. of Biostatistics, Assistant Professor, Department of Health, Ahvaz Jundishapur University of Medical Sciences, Ahvaz, Iran

${ }^{5}$ M.Sc. of Midwifery, Faculty Member, Department of Midwifery, Shoushtar Faculty of Medical Sciences, Shoushtar, Iran

\section{Type of article: Original}

\begin{abstract}
Background: One of the forms of violence that receives less attention due to cultural and social issues is sexual violence against women, which is a hidden and a constant epidemic and impact on their health.

Aim: This study aimed to determine the relationship between function and sexual satisfaction in women who have experienced sexual violence in Ahvaz-Iran.

Methods: This study was a case-control study which was conducted on 105 women (cases $=35$ and control=70) referred to one forensic center and seventeen Shahrivar health centers during 2013-2014 in Ahwaz-Iran. The data collection tools included questionnaires for evaluating demographic characteristics and sexual satisfaction, sexual female function index and sexual violence. The data were analyzed using descriptive and inferential statistics (Chi-square, Fisher's exact, and independent-samples t-test) in SPSS, version 19. P-value $<0.05$ was considered significant.

Results: Two groups of women were matched according to age and education. Mean \pm SD sexual satisfaction was $(71.4 \pm 15.84)$ in the case group and $(99.44 \pm 15.68)$ in the control group $(\mathrm{p}<0.001)$. The mean $\pm \mathrm{SD}$ of sexual function was (17.1 \pm 4.94$)$ in the case group and $(26.37 \pm 5.27)$ in the control group. The groups had a statistically significant difference in terms of sexual arousal, sexual orgasm, sexual lubrication, pain and sexual satisfaction $(\mathrm{p}<0.001)$.

Conclusion: Sexual dysfunction and dissatisfaction have a relation with sexual violence, and a major concern is that the sexual violence in most cases is hidden and can seriously affect the general health condition of women.
\end{abstract}

Keywords: Sexual function, Sexual satisfaction, Sexual violence, Women

\section{Introduction}

Violence against women is as old as human history and has existed since human barbarism and primitivism, through to the modern age $(1,2)$. Every year, more than 6.1 million people around the world die due to violence. Similarly, many are injured and suffer from physical, sexual, reproductive and mental problems $(3,4)$. According to the World Bank, rape and domestic violence is the cause of $19 \%$ of diseases in women aged between 19 and 44 years old in

\section{Corresponding author:}

Zahra Hatami-Manesh, Department of Midwifery, Menopause Andropause Research Center, Ahvaz Jundishapur University of Medical Sciences, Ahvaz, Iran.

Tel: +98.6142425019, Fax: +98.42427159, Email: Zahra.hatamimanesh2016@gmail.com

Received: March 15, 2017, Accepted: January 15, 2018, Published: April 2018

iThenticate screening: January 09, 2018, English editing: January 27, 2018, Quality control: March 14, 2018

This article has been reviewed / commented by four experts

(C) 2018 The Authors. This is an open access article under the terms of the Creative Commons Attribution-NonCommercialNoDerivs License, which permits use and distribution in any medium, provided the original work is properly cited, the use is non-commercial and no modifications or adaptations are made. 
industrialized countries. By the same token, rape and violence target the health of women aged between 15 and 44 years old more than diseases such as breast and uterus cancers and accidents $(5,6)$. The most common form of violence against women is the violence by a partner which is referred to as "domestic violence", which can be physical, sexual, emotional or financial (6). One form of violence which hasn't attracted enough attention due to cultural and social issues, is sexual violence against women which is a covert and consistent epidemic that can happen at any moment of women's lives and affect their health and happiness $(2,3)$. Sexual violence is defined as a sexual act committed against someone without that person's freely given consent, or any sexual act or attempt to obtain a sexual act by violence or coercion, acts to traffic a person or acts directed against a person's sexuality, regardless of the relationship to the victim (7). A study conducted in Brazil showed that, women in every period of their lives had experienced around $59.7 \%$ of sexual violence which $88 \%$ of them had been done by their husbands or sexual partners (8). A study in Tehran showed that $76 \%$ of women had experienced sexual violence (9). Most research done on women who have been abused in the past indicates that they will be at greater risks for sexual arousal problems and other forms of sexual problems. Researchers have shown that low sexual desire and infertility is far more common in these women (10).

Sexual activity and satisfaction are considered to be one of the most basic features of human life. Sexual satisfaction as one of the physiological needs, brings health and consequently, dissatisfaction and physical and mental pressures caused by it can lead anybody astray (11). Sexual satisfaction is under the effect of many factors, including job stresses, tension between spouses, education and culture levels, economical problems, moral and sexual consent, and each one's respective physical and mental problems and disease $(12,13)$. Adam et al. showed that sexual satisfaction of both partners was of utmost importance, and there was a direct relationship between the frequency of sex and sexual satisfaction between spouses (14). Research showed that there is a direct and meaningful relation between people's sexual performance and sexual satisfaction. Not paying enough attention to their sexual performance problems can cause sexual dissatisfaction and can even affect marital and family relations as time passes (15). Sexual disorder may be caused by psychological and physical factors. In another classification, organic and inorganic factors are known to cause sexual disorders (16). Studies on married women in Malaysia showed that the rate of sexual disorder was $29.6 \%$ and the rate of disorders in each field is respectively $67.8 \%$ in intercourse, $60.9 \%$ erection disorder, $59.1 \%$ orgasm disorder, $52.2 \%$ dissatisfaction, and 50.4 over lubrication of vagina (17). Consulting about sexual problems especially in Asian societies such as Iran have not been discussed generally and widely due to cultural and religious issues. Consequently, this may hinder providing appropriate services for the target group (18). Also considering the danger of sexual violence for human rights, having various interpretations about the concept, scope, and consequences of this violence and hidden feature of this type of violence among women in society on the one hand, and the limited studies in this area for the promotion, awareness and health of women and the family on the other hand, this study was designed to determine the relationship between sexual performance and sexual satisfaction in those who have experienced violence, so that we can take steps to improve the sexual health of women.

\section{Material and Methods}

\subsection{Research design and sample size}

This study was a case-control study that was conducted on 105 women referred to a forensic center and 17 Shahrivar health centers during 2013-2014 in Ahwaz -Iran. According to similar previous studies in the field (19), in which the rate of sexual disorder in two groups was expressed respectively, P1 (without violence) $9 \%$ and P2 (with sexual violence) $33 \%$, and expressed sample size to be $90 \%$ and confidence factor $95 \%$ using the NSCC software with 35 samples in the case group and, 70 samples in the control group from a total number of 105 samples were obtained.

\subsection{Selection criteria}

Inclusion criteria were: 1) age limit 15-45 years, 2) elapse of at least one year after marriage, and 3) sexually abused women referred to Ahwaz Forensics' women's medical examination unit,. Exclusion criteria included: 1) women referred for the reason of physical, mental and verbal violence, 2) having any critical incident in the last 6 months, 3) having a known illness and being under medical treatment, and 4) having a known psychological illness and being under psychotropic medical treatment.

\subsection{Sampling method}

Two groups of women are grouped according to age and education. The age groups are 15 to 20,21 to 26,27 to 32 , 33 to 38 and 39 to 45 , and the levels of education groups were classified in middle school, high school and university degree groups. To gather the data of the case group, the daily researcher referred to a forensic center in 
Ahwaz after explaining the purposes of the study, implementation and ensuring the officials about integrity and confidentiality of the results. At first, women presumed to be sexually abused and with a court letter were examined by a forensic specialist, and in the case of verifying the violence, they were asked to fill the violence questionnaire for which they could enter the study thereafter. To collect data from the control group, the researcher then referred to 17 Shahrivar health centers in Ahvaz, obtained consent and explained the confidentiality and anonymity of the questionnaires, and then began to fill the questionnaires of the women who had the criteria to enter the study.

\subsection{Measurement tools}

Questionnaires were used in two groups consisting of 3 parts, the first included demographic data (consisting of 15 questions) and questions of sexual violence (including 3 questions) (Questionnaire No. 1), the second part included Larson Sexual Satisfaction Questionnaire (Questionnaire No. 2), the third part included the Sexual Performance Index Questionnaire (Questionnaire No. 3).

2.4.1. Demographics Questionnaire:

Demographic data including age, education, occupation, husband's occupation, socioeconomic status, number of children, duration of marriage (years), age difference to spouse, smoking status and number of pregnancies. To achieve scientific validity, a demographic questionnaire was used by content validity in the way that after studying new books and essays, in order to review and modify it, the questionnaire was given to 10 faculty members of Ahwaz University of Medical Sciences and the final version was developed after conducting necessary reforms.

\subsubsection{Sexual Violence Questionnaire:}

The revised Conflict Tactics Scales (CTS2) is the most widely used instrument for measuring intimate partner violence. Sexual violence has 3 separate questions, and the minimum score obtained by any person is zero and the maximum score is 7 . According to research done to assess the reliability of the standard of the violence questionnaire in Iran, Cronbach's alpha coefficient of $87 \%$ was achieved $(20,21)$.

\subsubsection{Larson sexual satisfaction questionnaire:}

The Larson sexual satisfaction questionnaire is a 25 -item scale. Each question has 5 options based on the Likert scale (never, rarely, sometimes, often or always). Total scores of answering the questions fall into four categories: sexual dissatisfaction (score less than 50), low satisfaction (50-75), moderate satisfaction (75-100) and high satisfaction (score greater than 100). In analyzing the data, those answering sexual dissatisfaction or low satisfaction were given code 1 , and those answering moderate satisfaction or high satisfaction were given code 2 . This instrument has also been validated in Iran by Shahni et al., as Cronbach's alpha coefficient was used and the ratio of $93 \%$ was obtained. It is notable that the questionnaire's scale level has acceptable reliability and has been modified in Iran (22).

\subsubsection{Sexual Performance Index Questionnaire}

Female sexual function was assessed using the Sexual Performance Index Questionnaire. The scale consisted of 6 subscales including Libido, Sexual desire, Lubrication, Orgasm, Satisfaction and Pain that each subscale consisted of $3,3,4,3,3$ and 3 questions, respectively. A nineteen-question five-item questionnaire, in which zero score in each section represented no report of sexual activity in the last month, and the maximum score was 36 and scores less than 26 were considered as impaired performance (23). Validity and reliability of the Sexual Performance Index questionnaire have been confirmed in several studies. This instrument has also been validated in Iran by Mohammadi et al., as the reliability scale and subscale through Cronbach's alpha was calculated greater than $70 \%$, which showed a good reliability of this tool $(24,25)$.

\subsection{Statistical analysis}

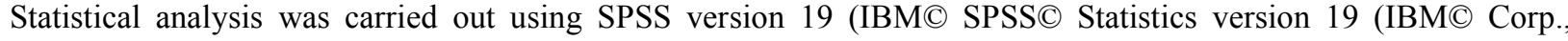
Armonk, NY, USA). Quantitative data were computed as means and standard deviations (SD) and qualitative data were presented as frequencies and percentages. Inferential statistics including Chi-square tests, independent-samples t-test, and Fisher's exact test were used to determine the relationship between sexual violence and sexual performance and sexual satisfaction. A p less than 0.05 was considered as a significant level throughout the study.

\subsection{Research Ethics}

The Ethics Committee of Ahwaz Jundishapur University of Medical Sciences (AJUMS) approved the study design (RHPRC: 9307). After obtaining permission from the Research Department of Ahwaz Jundishapur University of Medical Sciences, Department of Forensic Medicine and 17 Shahrivar health centers in Ahvaz, the researchers referred to these centers and the aim and method of the study were explained to the women. The participants were assured that their information would be kept confidential and they were free to leave the study at any time without 
any effect on their care. Also, written informed consent was obtained from the participants after a comprehensive explanation of the procedure involved.

\section{Results}

According to Table 1, the mean \pm SD of the women's age was $29 \pm 6.71$ and $28.25 \pm 7.29$ years in the control group and the case group, respectively. The highest frequency of education level of the participants was high school $(51.4 \%$ and $52.9 \%)$ in the case and control group, respectively. Most of the women in the case group were housewives $(82.9 \%)$. Regarding economic circumstances, most of the participants in the case and control groups $(54.3 \%$ and $84.3 \%)$ had moderate economic situation. The two groups were not significantly different in age, education level, occupation and spouse's occupation $(\mathrm{p}>0.05)$. However, significant difference was observed in terms of the duration of married life (duration of married life was more in the case group compared to that in the control group) and age difference with spouse (age difference with spouse was more than that in the control group), economic status, and addiction of spouse ( $\mathrm{p}>0.05$ ) (Chi-square test). According to the results of Table 2, the groups had a statistically significant difference in terms of sexual arousal, sexual orgasm, sexual lubrication, pain and sexual satisfaction $(\mathrm{p}<0.001)$. The mean and standard deviation of total score of sexual performance was respectively (26.37 \pm 5.27$)$ and (17.10 \pm 4.94$)$ in the control group and the case group, which showed that both groups had statistically significant differences regarding sexual performance $(\mathrm{p}<0.001)$ (independent-samples t-test). The mean and standard deviation of sexual satisfaction was observed at $(99.44 \pm 15.68)$ and $(71.4 \pm 15.84)$ in the control group and the case group, respectively. According to statistical analysis, there was significant difference between the two groups in terms of sexual satisfaction $(\mathrm{p}<0.001)$ (independent-samples t-test) (Table 3). About $95.7 \%$ of the control group and $45.72 \%$ of the case group had good satisfaction. The rate of low satisfaction was respectively $(4.3 \%)$ and $(54.19 \%)$ in the control group and the case group, which shows statistically significant difference between the two groups $(\mathrm{p}<0.001)$ (Fisher's exact test).

Table 1. The maternal and socioeconomic characteristics of the participants

\begin{tabular}{|c|c|c|c|c|}
\hline \multicolumn{2}{|l|}{ Variables } & $\begin{array}{l}\text { Case Group; Mean } \pm \text { SD / n } \\
(\%)\end{array}$ & $\begin{array}{l}\text { Control Group; Mean } \pm \text { SD / n } \\
(\%)\end{array}$ & $\begin{array}{l}\mathrm{p}- \\
\text { value }\end{array}$ \\
\hline \multicolumn{2}{|c|}{ Age (Years) } & $28.25 \pm 7.29$ & $29 \pm 6.71$ & 0.6 \\
\hline \multicolumn{2}{|c|}{ Duration of marriage (Years) } & $6.58 \pm 6.22$ & $9.74 \pm 7.15$ & 0.04 \\
\hline \multicolumn{2}{|c|}{ Age difference with spouse } & $3.29 \pm 7.74$ & $3.84 \pm 5.74$ & 0.01 \\
\hline \multirow[t]{3}{*}{ Women's education } & Secondary & $11(31.4)$ & $20(28.6)$ & \multirow[t]{3}{*}{0.45} \\
\hline & High school & $18(51.4)$ & $27(52.9)$ & \\
\hline & University & $6(17.1)$ & $13(18.6)$ & \\
\hline \multirow{3}{*}{$\begin{array}{l}\text { Husband's } \\
\text { education }\end{array}$} & Secondary & $12(34.3)$ & $16(22.9)$ & \multirow[t]{3}{*}{0.4} \\
\hline & High school & $18(51.4)$ & $45(64.3)$ & \\
\hline & University & $5(14.3)$ & $9(12.9)$ & \\
\hline \multirow[t]{2}{*}{ Woman's job } & Housewives & $29(82.9)$ & $62(88.6)$ & \multirow[t]{2}{*}{0.41} \\
\hline & Employees & $6(17.1)$ & $8(11.4)$ & \\
\hline \multirow[t]{3}{*}{ Husband's job } & Unemployed & $0(0.00)$ & $3(4.3)$ & \multirow[t]{3}{*}{0.41} \\
\hline & Employees & $30(85.7)$ & $55(78.6)$ & \\
\hline & $\begin{array}{l}\text { Self- } \\
\text { employed }\end{array}$ & $5(14.3)$ & $12(17.1)$ & \\
\hline \multirow[t]{4}{*}{ Number of children } & 0 & $11(31.4)$ & $12(17.2)$ & \multirow[t]{4}{*}{0.37} \\
\hline & 1 & $8(22.9)$ & $23(32.9)$ & \\
\hline & 2 & $10(28.6)$ & $21(30)$ & \\
\hline & $3 \leq$ & $6(17.1)$ & $14(20)$ & \\
\hline \multirow{2}{*}{$\begin{array}{l}\text { Husband's } \\
\text { addiction }\end{array}$} & have & $7(20)$ & $4(5.7)$ & \multirow[t]{2}{*}{$<0.001$} \\
\hline & haven't & $28(80)$ & $66(94.3)$ & \\
\hline \multirow[t]{3}{*}{ Economic situation } & weak & $8(22.9)$ & $5(7.1)$ & \multirow[t]{3}{*}{$<0.001$} \\
\hline & average & $19(54.3)$ & $59(84.3)$ & \\
\hline & good & $8(22.9)$ & $8(22.9)$ & \\
\hline
\end{tabular}

The data were analyzed using Chi-square and Fisher's exact test 
http://www.ephysician.ir

Table 2. Comparing the mean and standard deviation of sexual function domains in the case and control group

\begin{tabular}{|l|l|l|l|l|}
\hline \multicolumn{2}{|l|}{ Variables } & $\begin{array}{l}\text { Case Group }(\mathrm{n}=35) ; \text { Mean } \pm \\
\text { SD }\end{array}$ & $\begin{array}{l}\text { Control Group }(\mathrm{n}=70) ; \text { Mean } \pm \\
\text { SD }\end{array}$ & $\begin{array}{l}\mathrm{p}- \\
\text { value }\end{array}$ \\
\hline \multirow{2}{*}{$\begin{array}{l}\text { Sexual performance } \\
\text { domains }\end{array}$} & Libido & $5.63 \pm 3.94$ & $1.06 \pm 3.93$ & 0.98 \\
\cline { 2 - 5 } & $\begin{array}{l}\text { Sexual } \\
\text { desire }\end{array}$ & $0.77 \pm 2.60$ & $1.03 \pm 4.12$ & $<0.001$ \\
\cline { 2 - 5 } & Orgasms & $0.95 \pm 2.40$ & $0.95 \pm 4.70$ & $<0.001$ \\
\cline { 2 - 5 } & Lubrication & $1.04 \pm 3.29$ & $1.00 \pm 4.56$ & $<0.001$ \\
\cline { 2 - 5 } & Pain & $1.04 \pm 3.08$ & $1.01 \pm 4.68$ & $<0.001$ \\
\cline { 2 - 5 } & Satisfaction & $1.07 \pm 2.78$ & $1.01 \pm 4.77$ & $<0.001$ \\
\hline \multicolumn{2}{|l|}{ Total score of sexual performance } & $4.94 \pm 17.10$ & $5.27 \pm 26.37$ & $<01$ \\
\hline
\end{tabular}

The data were analyzed using independent-samples t-test

Table 3. Distribution and comparison of sexual satisfaction in both case-control groups

\begin{tabular}{|l|l|l|l|l|}
\hline Variables & $\begin{array}{l}\text { Case Group (n=35); Mean } \pm \\
\mathrm{SD} / \mathrm{n}(\%)\end{array}$ & $\begin{array}{l}\text { Control Group }(\mathrm{n}=70) ; \\
\text { Mean } \pm \text { SD / }(\%)\end{array}$ & $\begin{array}{l}\mathrm{p}- \\
\text { value }\end{array}$ \\
\hline \multicolumn{2}{|l|}{ Total mean of Sexual satisfaction } & $15.84 \pm 71.4$ & $15.68 \pm 99.44$ & $<0.001$ \\
\hline \multirow{2}{*}{$\begin{array}{l}\text { Sub-scales of Sexual } \\
\text { satisfaction }\end{array}$} & $\begin{array}{l}\text { Lack of } \\
\text { satisfaction }\end{array}$ & $1(2.9)$ & $1(1.4)$ & $<0.001$ \\
\cline { 2 - 5 } & Low & $21(60)$ & $2(2.9)$ & \\
\cline { 2 - 5 } & Moderate & $13(37.1)$ & $25(35.7)$ & \\
\cline { 2 - 5 } & Good & $0(0)$ & $42(60)$ & \\
\hline
\end{tabular}

The data were analyzed using Chi-square and independent-samples t-test

\section{Discussion}

The purpose of this study was to investigate the relationship between performance and sexual satisfaction in women who experienced sexual violence in Ahvaz-Iran. Sexual activity is one of the important dimensions of the life of individuals. This can be influenced by self-personality, interpersonal relationships, family, social and cultural conditions, environment, records of his sexual activities, husband and wife, physical and mental health and hormonal status of the individual (26). The findings of this study showed that the groups had a statistically significant difference in terms of sexual arousal, sexual orgasm, sexual lubrication, pain and sexual satisfaction but scores of desire did not show any significant difference. This is also consistent to the findings of Heiman et al., on 148 women (in three groups, 78 persons without sexual violence, 44 persons with experience of physical and sexual violence, and 26 persons with the experience of sexual violence) that there was no difference between the groups in sexual desire (27). Sexual desire is a natural and innate instinct of humans. It seems that sexual desire in addition to psychosocial issues, is affected under the stronger potential of Physiology and Endocrinology. Desire is a subjective feeling and a voluntary decision whether or not to have sexual activity (28). Research showed that victims of violence are less satisfied with their current sexual relationships and with the quality of their relationships with men. Fear of sex, arousal dysfunction and desire dysfunction were the most common sexual disturbances found in those victims $(29,30)$. In this study, sexual arousal in women was higher in the control group that there was a statistically significant difference $(\mathrm{p}<0.001)$. The findings of previous studies showed that women with experience of sexual violence had a more negative attitude in sexual arousal compared to the non-violence group, and the attitudes of women about sexual arousal was as fear, anger and disgust. This negative attitude of women with experience of physical or sexual violence was the highest and in women without a history of violence was lowest (27). It seems that the fear of violence causes disgust in a person and then increasing negative defense mechanisms in the development of sexual arousal in her, and a negative resistance, is caused in this step. The results revealed that the groups had a statistically significant difference in terms of sexual orgasm. The results of a study on 163 married women, 18-65 years old, in Malaysia revealed that orgasm disorder is $6.16 \%$ (31). Many researchers believe satisfaction and psychological security of the person during intercourse is an affecting factor on orgasm that this assumption cannot be made about violence and one without orgasms traverses the sexual cycle. In the study of Hosseini Tabaqdehi et al. on 899 women referred to health centers in Sari, disruption in lubrication was 39.8\% (31). Lubrication includes ionic content of vaginal fluid and mucosal secretions of Bartholin's gland which is achieved by the action of sexual tension in women who have been sexually aroused. Leitner's study found that women who had sexual violence, often suffered from painful intercourse (19). The pain cycle starts with fear, which consequently, causes stress and the result is the creation of spasms, followed by pain. It seems that the fear of violence can be 
predisposing to pain in people with sexual violence. According to the findings, both groups showed significant variance in terms of the mean of sexual satisfaction $(p<0.001)$. As well as an overall score of sexual performance, in women in the control group showed positive sexual performance of women in this study, and in the case group represented undesirable sexual performance. Many of these women may have limited awareness of their level of sexual response, making it much less likely that their level of functioning would strongly affect their level of sexual dysfunction. Sexual dysfunction and sexual satisfaction will have different consequences and may cause problems such as anger, violence, separation, and depression (32).

Ali Akbari Dehkordi, et al. showed that the average of sexual satisfaction was expressed as 5.54 and average sexual performance of women was 20.9 which is indicative of poor sexual performance, so a good sexual performance in women can be considered as women's health symptoms (33). In this study, the frequency of optimal sexual performance was $52.9 \%$ in the control group and in the case group was $0 \%$ which revealed a significant difference in both groups $(\mathrm{p}<0.001)$. In the study by Hosseini Tabaqdeh in Sari it was shown that the frequency of sexual dysfunction in the studied population was $45.2 \%$ (31). Auslander et al. showed that $85 \%$ of adults were satisfied with their sexual relationships, they believe that those who reported more satisfaction had more positive relationships with their spouse and less emotional sensitivity in their relationships, and were sexually active (34). A study by Castellanos-Torres showed that social factors affecting sexual satisfaction from a gender perspective revealed that sexual satisfaction in women who paid attention to them and feel good about them was 1.7 times higher than those who did not have this feeling (35). Violence against women can lead to low self-confidence, poor communication with the husband and his associates and depression in women, it can also cause nervousness and inability in concentration, and even the inability to perform daily activities, which, collectively, all these factors can cause a failure to satisfy the sexual desire and low sexual satisfaction in an abused person. It seems that during their lives, abused women have had to endure insults and humiliation from their husbands, and their feelings and sexual needs have been neglected and they have less sexual satisfaction than the control group.

\section{The strengths and limitations of the study}

The most difficult part of this study was interviewing abused women referred to the forensic center in Ahvaz, because clients referred to the above-mentioned center had special circumstances according to the complaint. To elaborate their questions, we required considerable time. However, because this was the first time that the questions were raised to them, their answers were very important and were of economic reality and totally reliable. Also, in the control group, understanding that the sexual relationship is the most private of marital matters and also because of cultural and religious restrictions in our society, people may simply not be able to talk about their sexual problems. So, dishonesty of some individuals to express their problems was outside of the restrictions of researcher, but researchers tried to eliminate this restriction, by using intimate and private relationships with the subjects. One notable instance was the side information that was obtained in this study.

\section{Conclusions}

According to the results of the sexual performance assessment and its components (sexual arousal, lubrication, orgasm, pain during intercourse, sexual satisfaction), there was a significant difference between two groups with and without violence. Also, sexual dysfunction and dissatisfaction had relation with sexual violence, the major concern about it is that the sexual violence in most cases is hidden and can seriously affect the general health situation of women.

\section{Acknowledgments:}

This article is derived from a MSc dissertation on Midwifery adopted by AJUMS with the ethical code of RHPRC: 9307. Thereby, we thank and appreciate the cooperation and assistance of the research deputy of AJUMS, Department of Midwifery of Menopause Research Center, Forensic Medical Center in Ahvaz, 17 Shahrivar health centers and all women participating in the study.

\section{Conflict of Interest:}

There is no conflict of interest to be declared.

Authors' contributions:

All authors contributed to this project and article equally. All authors read and approved the final manuscript. 


\section{References:}

1) Capaldi DM, Knoble NB, Shortt JW, Kim HK. A systematic review of risk factors for intimate partner violence. Partner abuse. 2012; 3(2): 231-80. doi: 10.1891/1946-6560.3.2.231.

2) Vameghi M, Mohammadreza KA, Sajadi H. Domestic Violence in Iran: Review of 2001-2008 literature. Social Welfare Quarterly. 2014; 13(50): 37-70.

3) Breiding MJ. Prevalence and characteristics of sexual violence, stalking, and intimate partner violence victimization - National Intimate Partner and Sexual Violence Survey, United States, 2011. Morbidity and mortality weekly report. 2014; 63(8): 1-18.

4) Hassan M, Kashanian M, Roohi M, Yousefi H. Maternal outcomes of intimate partner violence during pregnancy: study in Iran. Public health. 2014; 128(5): 410-5. doi: 10.1016/j.puhe.2013.11.007.

5) Devries KM, Mak JY, García-Moreno C, Petzold M, Child JC, Falder G, et al. The global prevalence of intimate partner violence against women. Science. 2013; 340(6140): 1527-8. doi: $10.1126 /$ science. 1240937 .

6) García-Moreno C. Global and regional estimates of violence against women: prevalence and health effects of intimate partner violence and non-partner sexual violence: World Health Organization; 2013.

7) DeGue S, Valle LA, Holt MK, Massetti GM, Matjasko JL, Tharp AT. A systematic review of primary prevention strategies for sexual violence perpetration. Aggression and Violent Behavior. 2014; 19: 346-62. doi: $10.1016 / j$.avb.2014.05.004.

8) Dircinha Teixeira de Araujo Moraes S, Maggio da Fonseca A, Bagnoli VR, Júnior José Maria Soares, de Moraes, Eli Mendes, Neves EMd, et al. Impact of domestic and sexual violence on women's health. Journal of Human Growth and Development. 2012; 22(2): 253-8.

9) Mohammadi G, Aliakbari SA, Ramezankhani A, Majd HA. The reproductive health status of women with experience of violence in harm reduction centers in Tehran, 2010. Pajoohandeh. 2011; 16(5): 219-25.

10) Watts $C$, Mayhew S. Reproductive health services and intimate partner violence: shaping a pragmatic response in Sub-Saharan Africa. International Family Planning Perspectives. 2004; 30(4): 207-13. doi: 10.1363/3020704. PMID: 15590387.

11) Litzinger S, Gordon KC. Exploring relationships among communication, sexual satisfaction, and marital satisfaction. Journal of sex \& marital therapy. 2005; 31(5): 409-24. doi: 10.1080/00926230591006719. PMID: 16169824.

12) Thomas HN, Hess R, Thurston RC. Correlates of sexual activity and satisfaction in midlife and older women. The Annals of Family Medicine. 2015; 13(4): 336-42. doi: 10.1370/afm.1820.

13) Zarbakhsh M, Dinani PT, Rahmani M. The relationship between sexual self-esteem and all its components with marital satisfaction in athletic women of Tehran. European Online Journal of Natural and Social Sciences. 2013; 2(2): 200.

14) Christensen S. The Effects of Premarital Sexual Promiscuity on Subsequent Marital Sexual Satisfaction. US: School of Family Life Brigham Young University; 2004.

15) Tavacol Z, Mirmolaei T, Moemenymovahed Z. Investigate the association between sexual function and sexual satisfaction in women referred to health centers in Tehran city. Journal of Nursing and Midwifery. 2012; 19(2).

16) Shahvary Z, Gholizade L, Hoseiny S. Determination of some related factors on women sexual satisfaction Gachsaran (South-West of Iran). Journal of Gorgan University of medical sciences. 2010; 11(4): 51-6.

17) Sidi H, Puteh S, Abdullah N, Midin M. The prevalence of sexual dysfunction and potential risk factors that may impair sexual function in Malaysian women. J Sex Med. 2007; 4(2): 311-21. doi: 10.1111/j.17436109.2006.00319.x. PMID: 17040486.

18) Radziah M, Shamsuddin K, Jamsiah M, Normi M, Zahari T, Syimah A, et al. Early resumption of sexual intercourse and its determinants among postpartum Iban mothers. Int J Reprod Contracept Obstet Gynecol. 2013; 2(2): 124-9. doi: 10.5455/2320-1770.ijrcog20130603.

19) Leithner K, Assem-Hilger E, Naderer A, Umek W, Springer-Kremser M. Physical, sexual, and psychological violence in a gynaecological-psychosomatic outpatient sample: Prevalence and implications for mental health. European Journal of Obstetrics \& Gynecology and Reproductive Biology. 2009; 144(2): 168-72. doi: 10.1016/j.ejogrb.2009.03.003.

20) Ebrahimipoor H. The first sexual experience of married women Shhrsbzvar a phenomenological study. Journal of Obstetrics Gynecology and Infertility Medical Sciences, Mashhad, Iran. 2010; 15(4).

21) Straus MA, Mickey EL. Reliability, validity, and prevalence of partner violence measured by the conflict tactics scales in male-dominant nations. Aggression and Violent Behavior. 2012; 17(5): 463-74. doi: 10.1016/j.avb.2012.06.004. 
22) Malecfazli H, Mehdizade M. Review of domestic violence against women in the city. Islamic Azad University of Medical Sciences. 2010; 15(2): 101-19.

23) Rahmani A, Merghatikhoeei E, Sadeghi N. Sexual satisfaction and marital satisfaction. Journal Nursing Care Research Center Tehran University of Medical Sciences. 2011; 24(70): 82-90.

24) Ghassamia M, Asghari A, Shaeiri MR, Safarinejad MR. Validation of psychometric properties of the Persian version of the Female Sexual Function Index. Urol j. 2013; 10(2): 878-85. PMID: 23801471.

25) Mohammadi K, Heydari M, Faghihezadeh S. The Female Sexual Function: Validation of The Iranian Version. Payesh. 2008; 7(3): 269-78.

26) Bigras N, Godbout N, Briere J. Child Sexual Abuse, Sexual Anxiety, and Sexual Satisfaction: The Role of Self-Capacities. Journal of Child Sexual Abuse. 2015; 24: 464-83. doi: 10.1080/10538712.2015.1042184. PMID: 26301436.

27) Heiman JR. Sexual dysfunction: Overview of prevalence, etiological factors, and treatments. Journal of sex research. 2002; 39(1): 73-8. doi: 10.1080/00224490209552124. PMID: 12476261.

28) Schloredt K, Heiman J. Perceptions of sexuality as related to sexual functioning and sexual risk in women with different types of childhood abuse histories. J Trauma Stress. 2003; 16: 275-84. doi: 10.1023/A:1023752225535. PMID: 12816341.

29) Karanfil R, Keten A, Zeren C, Arslan M, Eren A. Evaluation of sexual assaults in Turkey. J Forensic Legal Med. 2013: 1-4. doi: 10.1016/j.jflm.2013.03.018.

30) Mohammed GF, Hashish R. Sexual violence against females and its impact on their sexual function. Egyptian Journal of Forensic Sciences. 2014; 5(3): 96-102. doi: 10.1016/j.ejfs.2014.08.004.

31) Hoseini Tabaghdehi M, Hoseini F. The Relative Frequency of Sexual Dysfunction and Some related Factors in the Women Referred to the Health Centers of Sari City (2006). Journal of Mazandaran University of Medical Sciences. 2012; 22(91).

32) Mazinani R, Akbari- Mehr M, Kaskian A, Kashanian M. Evaluation of prevalence of sexual dysfunctions and its related factors in women. Razi J Med Sci. 2012; 19(105): 59-66.

33) Aliakbari Dehkordi M. Relationship between women sexual function and marital adjustment. Journal of Behavioral Sciences. 2010; 4(3): 11-2.

34) Auslander BA, Rosenthal SL, Fortenberry JD, Biro FM, Bernstein DI, Zimet GD. Predictors of sexual satisfaction in an adolescent and college population. Journal of pediatric and adolescent gynecology. 2007; 20(1): 25-8. doi: 10.1016/j.jpag.2006.10.006.

35) Castellanos-Torres E, Álvarez-Dardet C, Ruiz-Muñoz D, Pérez G. Social determinants of sexual satisfaction in Spain considered from the gender perspective. Annals of Epidemiology. 2013; 23(3): 150-6. doi: 10.1016/j.annepidem.2012.12.010. 